\title{
Natural Convection in an Enclosure: Effect of Magnetic Field Dependent Thermal Conductivity
}

\author{
Mohammadhossein Hajiyan, Shohel Mahmud, Mohammad Biglarbegian, Hussein A. Abdullah \\ School of Engineering, University of Guelph \\ 50 Stone Rd. East, N1G 2W1, Guelph, Canada \\ mhajiyan@uoguelph.ca; smahmud@uoguelph.ca; mbiglarb@uoguelph.ca;habdulla@uoguelph.ca
}

\begin{abstract}
In this paper, the natural convection heat transfer process is investigated inside an annular enclosure filled with a magnetic nanofluid $\left(\mathrm{Fe}_{3} \mathrm{O}_{4}\right.$ magnetic nanoparticles dispersed in Kerosene). A uniform magnetic field $(H)$ is applied along the axial direction of the enclosure. Thermal conductivity $(k)$ is considered as a function of magnetic field. A nonlinear relationship between magnetic field and thermal conductivity in the magnetic nanofluid (MNF) is assumed and interpolated. Finite element method is utilized to solve the governing equations and calculate the Nusselt number and it is presented as a function of volume fraction and magnetic field strength. The results show the significant effect of applied magnetic field on heat transfer rate, more specifically on $\mathrm{Nu}$, in the enclosure when higher volume fractions of nanoparticles are used. Thermal conductivity enhancement as a result of using magnetic field can be used for various applications such as thermal energy storage in which the heat transfer needs to be accurately controlled.
\end{abstract}

Keywords: Magnetic nanofluid (MNF), Thermal conductivity, Lorentz force, Natural convection

$\begin{array}{ll}\text { Nomenclature } & \\ B & \text { Magnetic flux density [T] } \\ B_{y} & \text { Component of magnetic flux density } \\ C_{p} & \text { Heat capacitance at constant temperature [J/kg.K] } \\ d & \text { Diameter of nanoparticle [nm] } \\ d_{p} & \text { Diameter of nanoparticles [nm] } \\ E & \text { Electrical field [V/m] } \\ J & \text { Current density [A/m2] } \\ K & \text { Pyromagnetic coefficient } \\ k & \text { Thermal conductivity [W/m.K] } \\ L & \text { Characteristic Length [m] } \\ M & \text { Magnetization respect to temperature } \\ T & \text { Temperature [K] } \\ x, y & \text { Space coordinates [m] } \\ u, v & \text { Velocity components in the } x \text { and } y \text { directions [m/s] } \\ \text { Greek symbols } & \\ \alpha & \text { Thermal diffusivity [m } 2 / \mathrm{s}] \\ \beta & \text { Coefficient of thermal expansion }[1 / \mathrm{K}] \\ \chi & \text { Magnetic Susceptibility } \\ v & \text { Kinematic viscosity [m } 2 / \mathrm{s}] \\ \mu & \text { Dynamic viscosity [kg/ms] } \\ \sigma & \text { Electrical conductivity }\left[(\Omega . m)^{-1}\right] \\ \rho & \text { Density [kg/m3] } \\ \phi & \text { Volume fraction [\%] } \\ S u b s c r i p t s & \\ c & \text { Cold } \\ h & \text { Hot } \\ c u & \text { Curie } \\ f & \text { Fluid } \\ s & \text { Solid } \\ n f & \text { Nanofluid } \\ & \end{array}$




\section{Introduction}

Heat transfer enhancement has been a challenging topic for researchers for many years to enhance the efficiency of many applications such as cooling and electronic equipments and solar systems. Numerous studies have been carried out on passive and active heat transfer systems to increase their efficiencies [1,2]. One of the effective ways to improve the heat transfer rate in fluids is adding conductive nanoparticle to the fluid [3]. In addition, the use of magnetic field in thermal process provides more opportunities for a wide range of applications such as thermal energy storage systems, magnetic refrigeration systems, and thermal batteries [4]. Beside the heat transfer enhancement, the main advantage of MNF is capability of being controlled via external magnetic field. Such a unique behaviour of this type of fluid (MNF) in the presence of a magnetic field creates opportunities in different applications like biomedical, electrical, and thermal engineering systems.

Magnetic nanoparticles are suspended in the carrier/base fluid and subjected to the gravitational and magnetic field; thus, the particle sedimentation is a factor that has to be taken into account. Also, the interaction and forces between nanoparticles, which causes Brownian motion, directly depend on size of the nanoparticle. In some researches the effect of Brownian motion are considered, whereas, in the others it was neglected. A summary of literature reviewed on thermal enhancement using magnetic nanofluids for different enclosures is tabulated in Table 1.

Table 1: Summary of previous studies on MNF with magnetic field for different geometry.

\begin{tabular}{|c|c|c|c|c|}
\hline Author(s) & Year & Geometry & Material & $\begin{array}{c}\text { Outcome } \\
\text { Contribution summary }\end{array}$ \\
\hline Mukhopadhyay et. al. [6] & 2005 & Square enclosure & Water/oil-based & $\begin{array}{c}\text { Boussinesq assumption } \\
\text { heat transfer rate improved }\end{array}$ \\
\hline Blums et. al. [7] & 2008 & $\begin{array}{c}\text { Cylinder } \\
\text { (50 } \mathrm{mm} \text { length and } 5 \mathrm{~mm} \text { diameter) }\end{array}$ & $\begin{array}{l}\text { Porcelain cylinder } \\
\text { oleic acid }\end{array}$ & $\begin{array}{l}\text { Thermomagnetic investigation } \\
\text { body forces- possible to increase } R_{a_{m}} \\
\text { exceed } 20 \text { times more than } R_{a_{T}}\end{array}$ \\
\hline Ming et. al. [8] & 2009 & Annulus & Water-based $\mathrm{Fe}_{3} \mathrm{O}_{4}$ & $\begin{array}{l}\text { Optimal working fluid ratio (53.5\%) } \\
\text { for the specific geometry }\end{array}$ \\
\hline Zablotsky et. al. [9] & 2009 & Rectangular & Ferrofluid, Mn-Zn particle & $\begin{array}{l}\text { Cooling via thermomagnetic convection } \\
\text { if heat source is in } \\
\text { maximal magnetic field intensity }\end{array}$ \\
\hline Fang et. al. [10] & 2009 & Cubic micro enclosure & Not specified & $\begin{array}{l}\text { Direct relation between chainlike cluster } \\
\text { and particle volume fraction }\end{array}$ \\
\hline Ashouri et. al. [11] & 2010 & Square cavity & Various ferrofluids & General correlation for $N u$ and its error \\
\hline Aminfar et. al. [12] & 2012 & Triangular enclosure & CuO-Water & $\begin{array}{l}\text { Studies on different } \mathrm{Ra} \mathrm{Ha} \text { numbers } \\
\text { to obtain highest heat transfer rate }\end{array}$ \\
\hline Sheikholeslami et. al. [13] & 2014 & L-shaped enclosure & $\mathrm{Al}_{2} \mathrm{O}_{3}$ & $\begin{array}{l}\text { Heat transfer using control volume } \\
\text { using KKL by inclination angle }\end{array}$ \\
\hline Mustafa et. al. [14] & 2014 & Vertical channel & Not specified & $\begin{array}{l}\text { Mathematical model for peristaltic } \\
\text { motion in vertical channel }\end{array}$ \\
\hline Rashidi et. al. [15] & 2015 & $\begin{array}{l}\text { Square enclosure } \\
\text { (obstacle embedded) }\end{array}$ & Not specified & Flow separation via magnetic field \\
\hline
\end{tabular}

It can be seen from the Table 1 that many numerical investigations are carried out for various enclosure geometries. Based on the achievements of previous studies in Table 1, thermal conductivity $(k)$ is an important parameter to improve the heat transfer rate. To the best of the authors' knowledge, no numerical study is conducted in which thermal conductivity was a function of both magnetic field $(H)$ and volume fraction $(\phi)$. Thus, in this study we proposed an annular enclosure with specific geometry subjected to uniform magnetic field and analysed the heat transfer. Fig. 1 shows the enclosure filled with pure kerosene as a base fluid and $\mathrm{Fe}_{3} \mathrm{O}_{4}$ as magnetic nanoparticle. The material of the enclosure is acrylic glass and inner pipe is copper. The properties of pure kerosene and $\mathrm{Fe}_{3} \mathrm{O}_{4}$ are provided in Table 2.

Table 2: Properties of kerosene and $\mathrm{Fe}_{3} \mathrm{O}_{4}[17,18]$.

\begin{tabular}{|c|c|c|c|c|c|c|c|}
\hline & $\rho\left(\mathrm{kg} / \mathrm{m}^{3}\right)$ & $C_{p}(j / \mathrm{kg} . \mathrm{k})$ & $k(W / m . k)$ & $d_{p}(\mathrm{~nm})$ & $\sigma(\Omega \cdot m)^{-1}$ & $\mu(\mathrm{kg} / \mathrm{m} . \mathrm{s})]$ & $\beta[1 / K]$ \\
\hline Kerosene (pure) & 788 & 2010 & 0.129 & - & $5 \mathrm{e}-11$ & 0.00164 & $800 \mathrm{e}-6$ \\
$\mathrm{Fe}_{3} \mathrm{O}_{4}$ & 5200 & 670 & 6 & 47 & 25000 & - & $1.3 \mathrm{e}-5$ \\
\hline
\end{tabular}



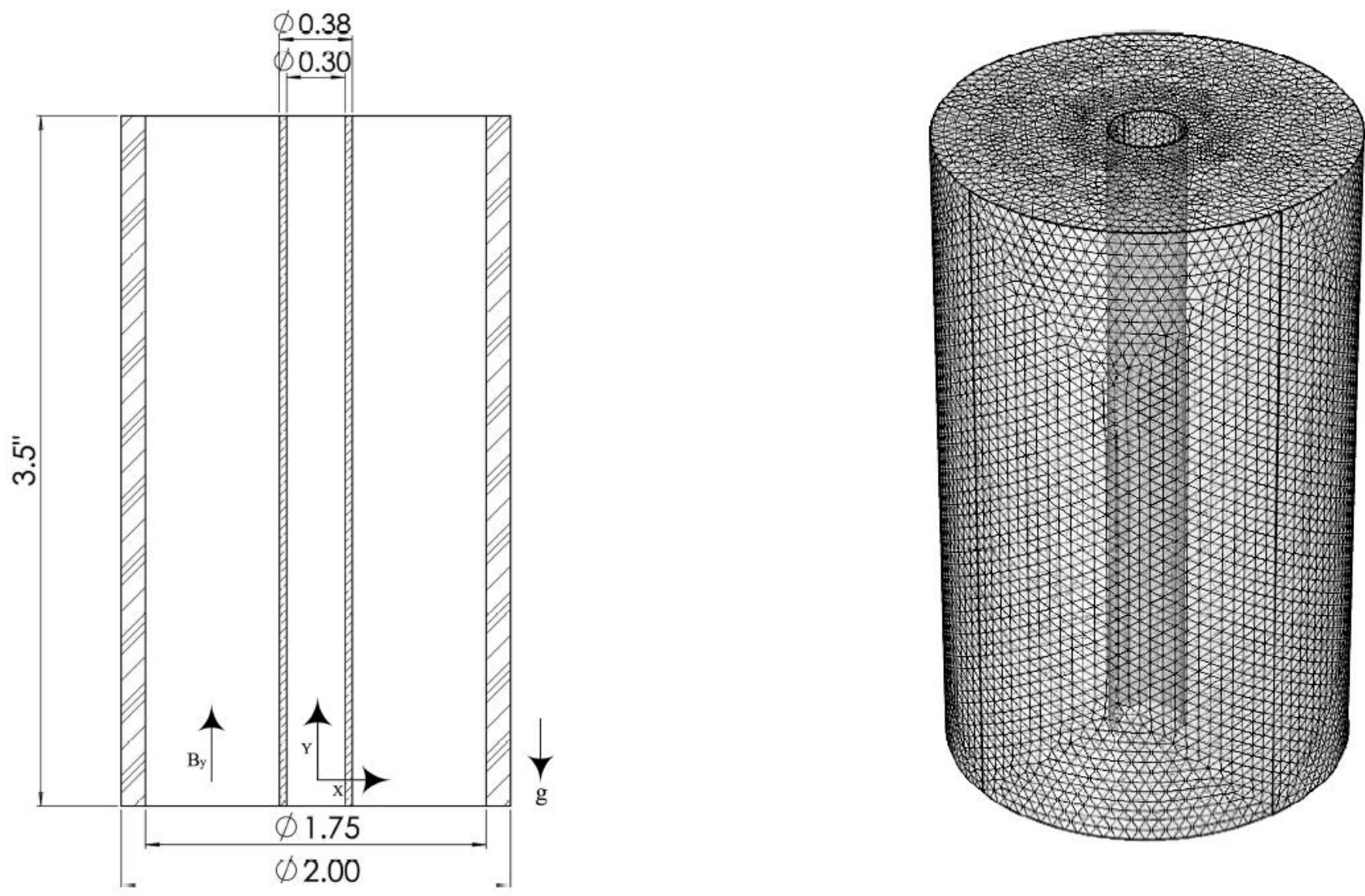

Fig. 1: Cross-section view and mesh distribution of the enclosure filled with kerosene- $\mathrm{Fe}_{3} \mathrm{O}_{4}$.

\section{Mathematical Modelling and Boundary Conditions}

In this study, it is assumed that the flow is laminar and steady, and the MNF is incompressible. In addition, the effect of Brownian motion is neglected. To simulate the heat transfer through the magnetic nanofluid and assuming Boussinesq approximation, we derived the conservation of mass, momentums and energy equations as follow:

$$
\frac{\partial u}{\partial x}+\frac{\partial v}{\partial y}=0
$$

where $u$ and $v$ are the velocity vectors in the $\mathrm{x}$ and $\mathrm{y}$ direction, respectively

$$
\begin{gathered}
\rho_{n f}\left(u \frac{\partial u}{\partial x}+v \frac{\partial u}{\partial y}+u \frac{\partial v}{\partial x}+v \frac{\partial v}{\partial y}\right)=-\frac{\partial P}{\partial x}-\frac{\partial P}{\partial y}+\mu_{n f}\left(\frac{\partial^{2} u}{\partial x^{2}}+\frac{\partial^{2} u}{\partial y^{2}}+\frac{\partial^{2} v}{\partial x^{2}}+\frac{\partial^{2} v}{\partial y^{2}}\right) \\
+\mu_{0} M\left(\frac{\partial H}{\partial x}+\frac{\partial H}{\partial y}\right)+\sigma_{n f}\left(B_{x} B_{y} v+B_{x} B_{y} u-B_{y}^{2} u-B_{x}^{2} v\right) \\
\rho_{n f} C_{p_{n f}}\left(u \frac{\partial T}{\partial x}+v \frac{\partial T}{\partial y}\right)=k_{n f}\left(\frac{\partial^{2} T}{\partial x^{2}}+\frac{\partial^{2} T}{\partial y^{2}}\right)-\mu_{0} T \frac{\partial M}{\partial T}\left(u \frac{\partial H}{\partial x}+v \frac{\partial H}{\partial y}\right) \\
+\mu_{n f}\left[2\left(\frac{\partial u}{\partial x}\right)^{2}+2\left(\frac{\partial v}{\partial y}\right)^{2}+\left(\frac{\partial v}{\partial x}+\frac{\partial u}{\partial y}\right)^{2}\right]
\end{gathered}
$$


Note that the last two terms in Eq. 2 are the magnetization force and Lorentz force which occur between the ferromagnetic particle in the presence of magnetic field.

$$
M=K H\left(T_{c u}-T\right)
$$

where $K$ is a constant, $H$ is magnetic field intensity, $T$ is the temperature of MNF, and $T_{c u}$ is Curie temperature., The Lorentz force that depends on the electrical conductivity of the MNF and velocity of nanoparticles, is calculated as follows:

$$
B=\mu_{0}(M+H)
$$

where $\mu_{0}$ is the magnetic permeability of vacuum $\left(4 \pi \times 10^{-7}\right)$, $\mathrm{H}$ is the magnetic field intensity $(A / m)$, and $B$ is magnetic flux density $(T)$. In order to solve the magnetic field inside the enclosure in this study, Maxwell's equations are used as follow:

$$
\begin{gathered}
\nabla . \mathbf{B}=0 \\
\nabla \times \mathbf{H}=0 \\
\mathbf{E}=\mathbf{V} \times \mathbf{B} ; \mathbf{J}=\sigma \mathbf{E} \\
\mathbf{F}=\mathbf{J} \times \mathbf{B}
\end{gathered}
$$

Finite element method with higher mesh density along the boundaries is used to solve the governing equations. In our simulation we assumed no slip-velocity condition on the walls. Hot surface is the copper pipe where the hot fluid passes through it and cold surface is glass. Having steady two phase flow inside the enclosure and isothermal condition on top and the bottom of the enclosure, we have the following boundary conditions:

$$
\begin{cases}x=R_{\text {in }}, 0<y<L: & u=o, v=o, T=T_{h} \\ x=R_{\text {out }}, 0<y<L: & u=o, v=o, T=T_{c} \\ y=0,0<x<r: & u=o, v=0, \frac{\partial T}{\partial y}=0 \\ y=L, 0<x<r: & u=0, v=0, \frac{\partial T}{\partial y}=0\end{cases}
$$

where $L$ is the height of the enclosure $(3.5 \mathrm{inch})$ and the radial distance between the inner pipe and the outer acrylic glass is $22.24 \mathrm{~mm}\left(R_{\text {out }}-R_{\text {in }}\right)$. Using polynomial curve fitting, we obtained the thermal conductivity as a function of volume fraction $\phi$ and magnetic field $\mathrm{H}$ from the literature [19]. In our study, we chose five different volume fractions $(1.115 \%$, $1.7 \%, 2.23 \%, 3.465 \%$, and $4.7 \%$ ) for numerical investigation. To compare and validate our simulation results with previous studies in which $\mathrm{Ra}$ versus $\mathrm{Nu}$ is provided (no magnetic field and no nanoparticles), we defined the Rayleigh number as $R a=\frac{g \beta \Delta T L^{3}}{v \alpha}$ and the Nusselt number on the hot surface as follows:

$$
N u_{\text {local }}=\frac{h L}{k_{f}}
$$


where $L$ is effective length and $\mathrm{h}$ is the heat transfer coefficient $\left(h=\frac{q_{n}}{T_{h}-T_{c}}\right) . q_{n}$ is normal heat flux from the wall and can also be expressed as $q_{n}=-k_{n f}\left(\frac{\partial T}{\partial X}\right)$.Finally, we calculated the average Nusselt number along the hot wall as follows:

$$
\overline{N u}=\frac{1}{L} \int_{0}^{L}-\left(\frac{k_{n f}}{k_{f}}\right) \frac{\frac{\partial T}{\partial X}}{\Delta T} d Y
$$

\section{Results and Discussions}

In order to validate the numerical scheme and accuracy of the simulation, the Nusselt number is plotted versus Rayleigh number, when the Prandlt number (Pr) is about 0.7. The results show the good agreement when compared with available literatures in the Fig. 2.

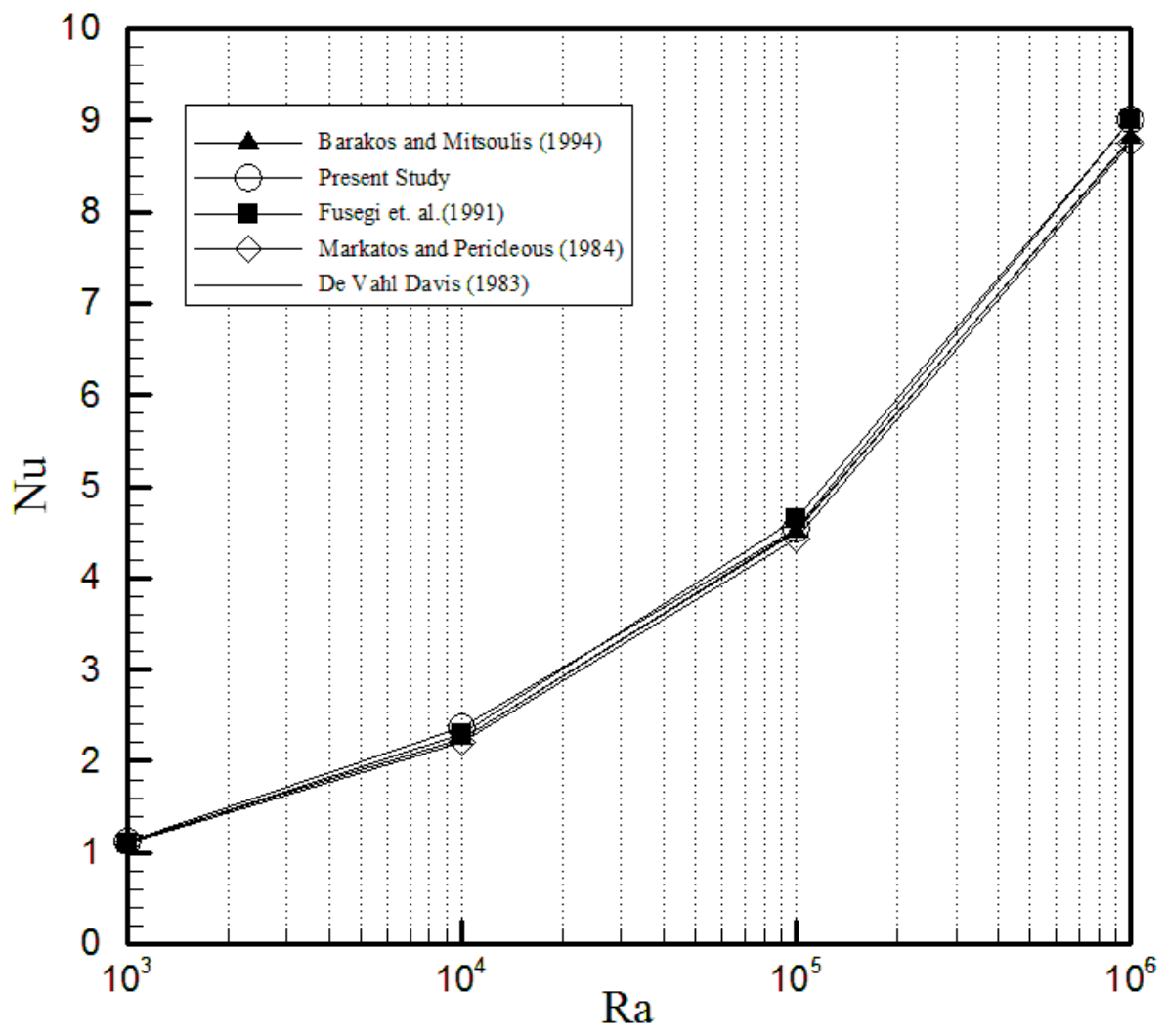

Fig. 2: Nusselt numbet versus Rayleigh number for the present study compared with other literatures $(\phi=0, \mathrm{H}=0$, and $\operatorname{Pr}=0.7)$. 


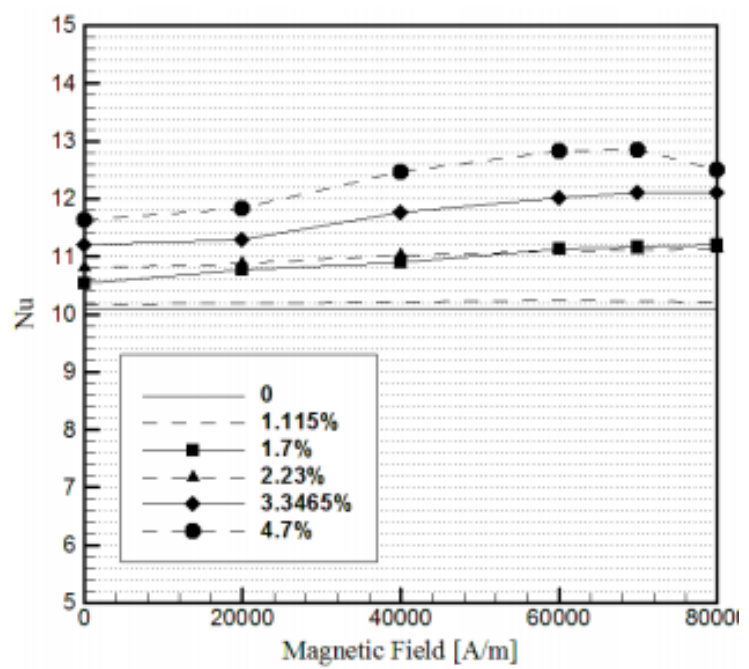

Fig. 3: $R a=10^{2}$.

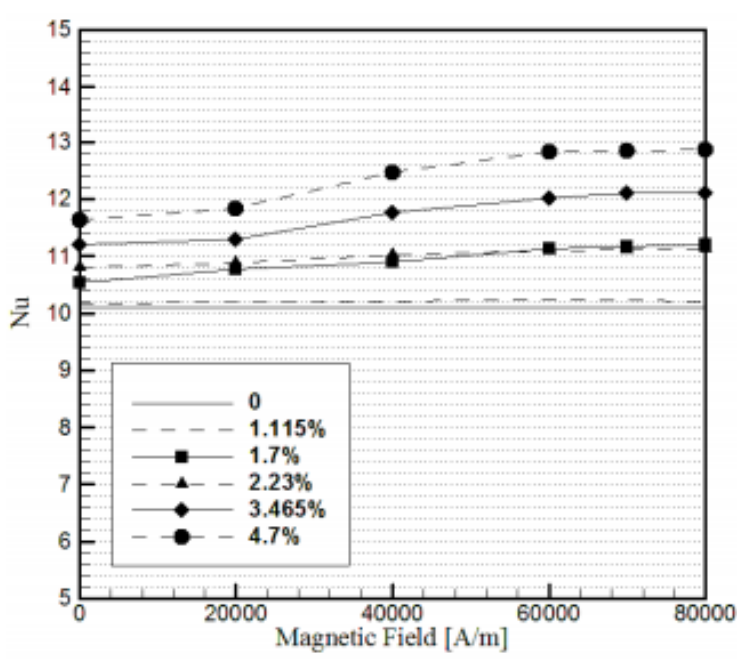

Fig. 4: $R a=10^{3}$.

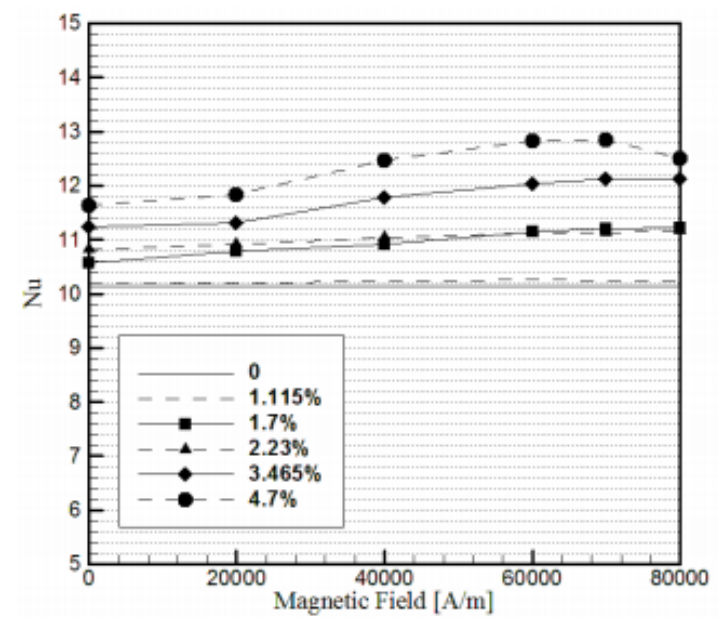

Fig. 5: $R a=10^{4}$. 


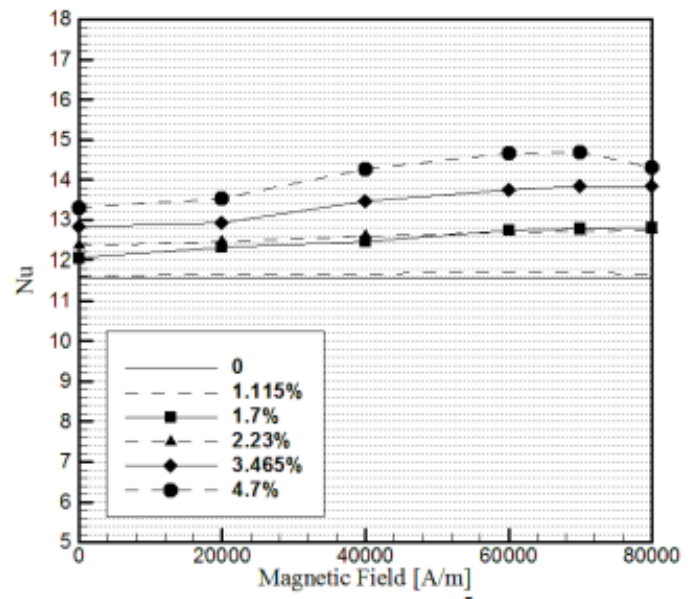

Fig. 6: $R a=10^{5}$.

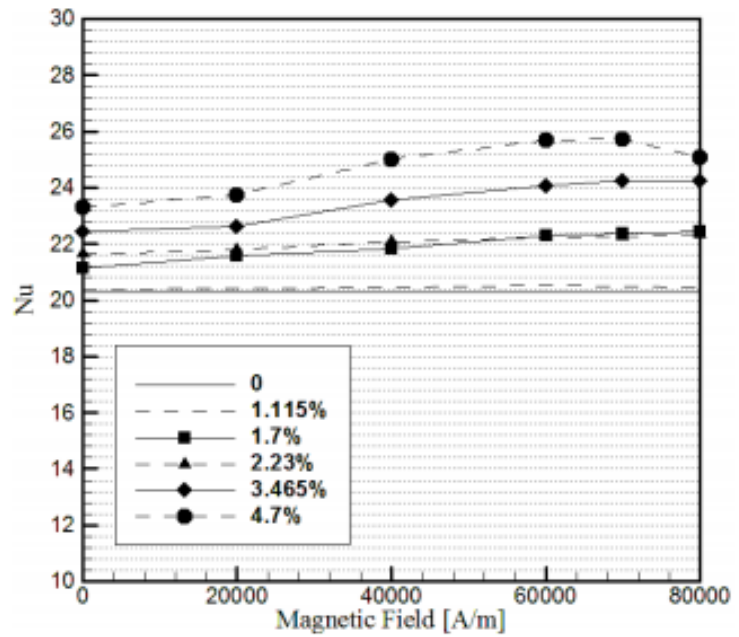

Fig. 7: $R a=10^{6}$.

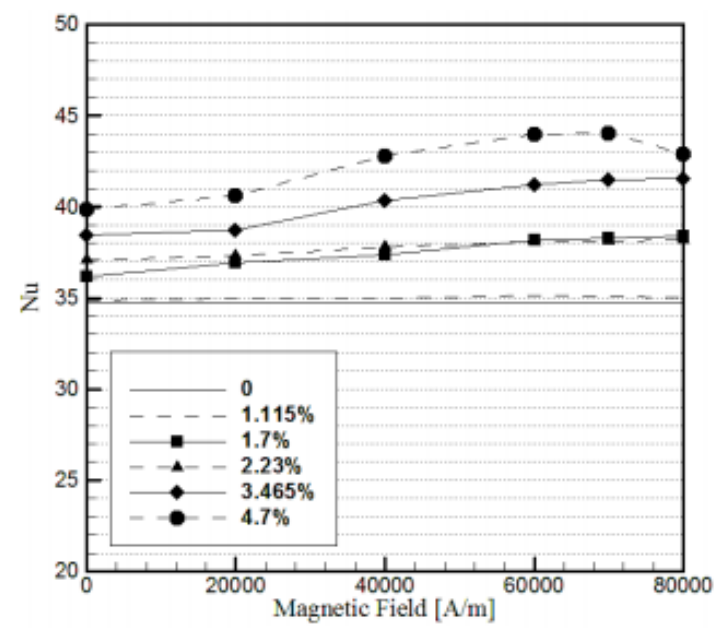

Fig. 8: $R a=10^{7}$.

Fig. 3-Fig. 8 show the effect of magnetic field on Nusselt number when Rayleigh is changing from $10^{2}$ to $10^{2}$ for various volume fractions of nanoparticle in kerosene. As can be seen from Fig. 3-Fig. 8 increasing the magnetic field with higher volume fraction results in increasing Nu markedly. From Fig. 3- Fig. 8, there is a slight decrease observed for high 
volume fraction approximately at $70 \times 10^{3}[\mathrm{~A} / \mathrm{m}]$; this can be explained due to the atomic motion of the particles and/or induction heating occurred inside the enclosure. To investigate the change of the $\mathrm{Nu}$ versus $\mathrm{Ra}$ for various magnetic field, Fig 9 and Fig 10 are provided below for two specific volume fractions ( $\phi=1.115 \%$ and $\phi=4.7 \%)$.

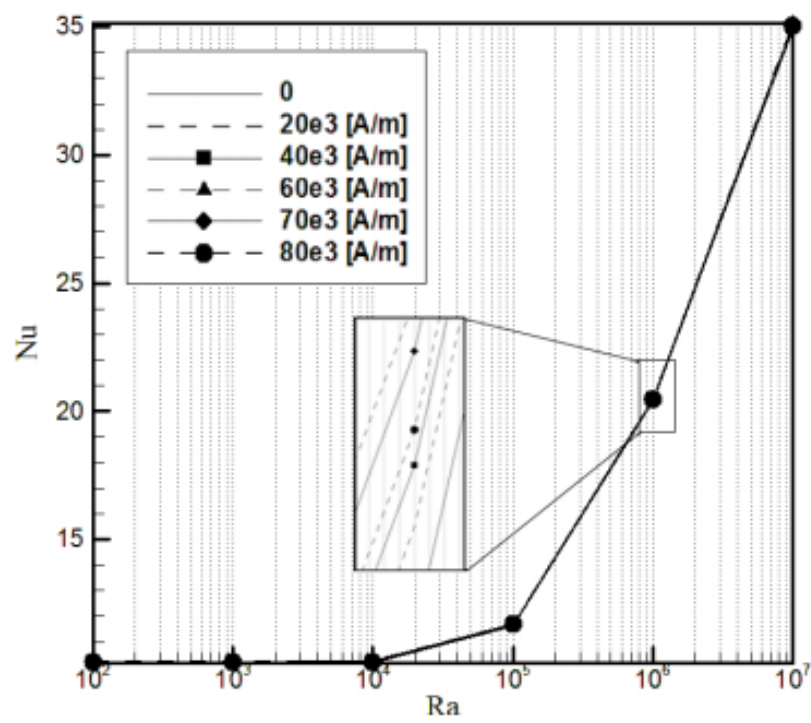

Fig. 9: Ra versus Nu when $\phi=1.115 \%$.

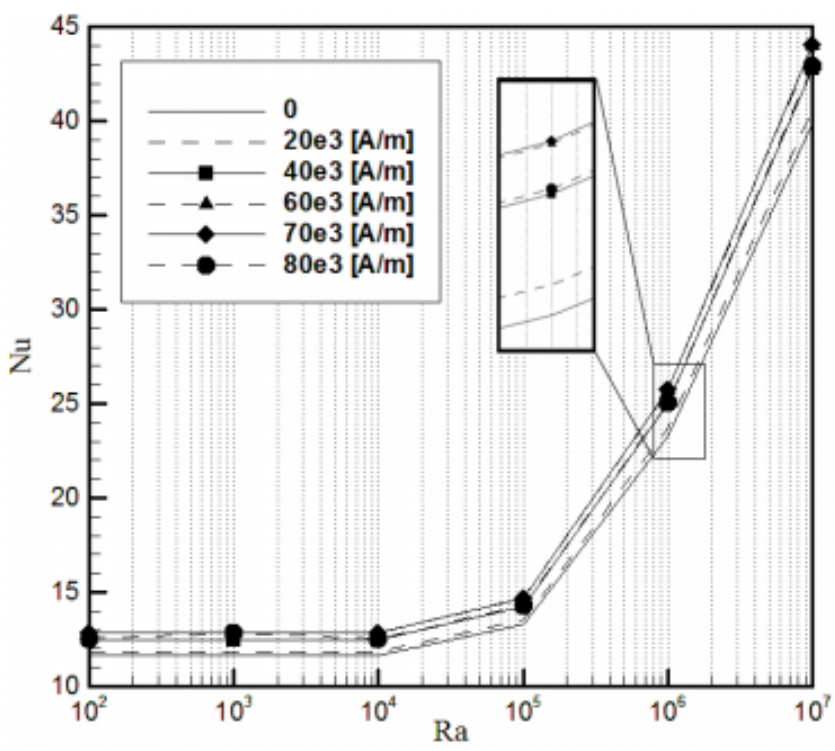

Fig. 10: Ra versus Nu when $\phi=4.7 \%$.

Fig. 11 and Fig. 12 illustrate the temperature distribution (steady-state) for different Rayleigh number when $\phi$ is constant $(\phi=4.7 \%)$. The uniform conduction like temperature distribution is observed in the Fig. 11 when Ra is $10^{2}$ compared to Fig. 12 when Ra increased. 


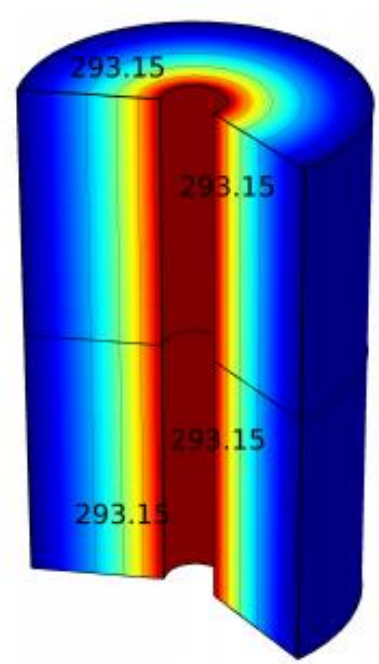

Fig. 11: Temperature distribution $\left(\mathrm{Ra}=10^{2}, \phi=4.7 \%\right.$, and $\left.\mathrm{H}=80 \times 10^{3}[\mathrm{~A} / \mathrm{m}]\right)$.

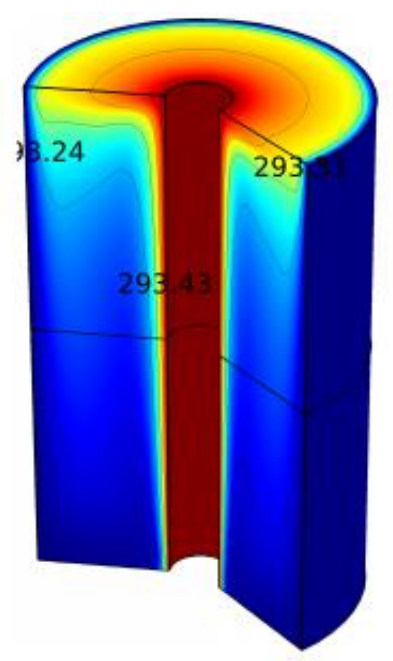

Fig. 12: Temperature distribution ( $\mathrm{Ra}=10^{7}, \phi=4.7 \%$, and $\left.\mathrm{H}=80 \times 10^{3}[\mathrm{~A} / \mathrm{m}]\right)$.

In addition, the velocity of flow is being affected due to the Lorentz force induced in the MNF in the presence of applied magnetic field. Thus, we defined dimensionless velocity to discuss this phenomena as follows [20]:

$$
\begin{aligned}
\delta_{T} & \sim L R a^{-1 / 4} \\
v & \sim \frac{\alpha_{n f}}{L} R a^{1 / 2}
\end{aligned}
$$

where $\delta_{\mathrm{T}}$ is the thermal thickness and $\alpha_{n f}$ is a thermal diffusivity of MNF which is related to thermal conductivity $(k)$; and $k$ itself,as previously discussed, is the function of magnetic field. The calculated velocity is divided by reference velocity (Eq. 14) and plotted along the radial distance of the enclosure. 


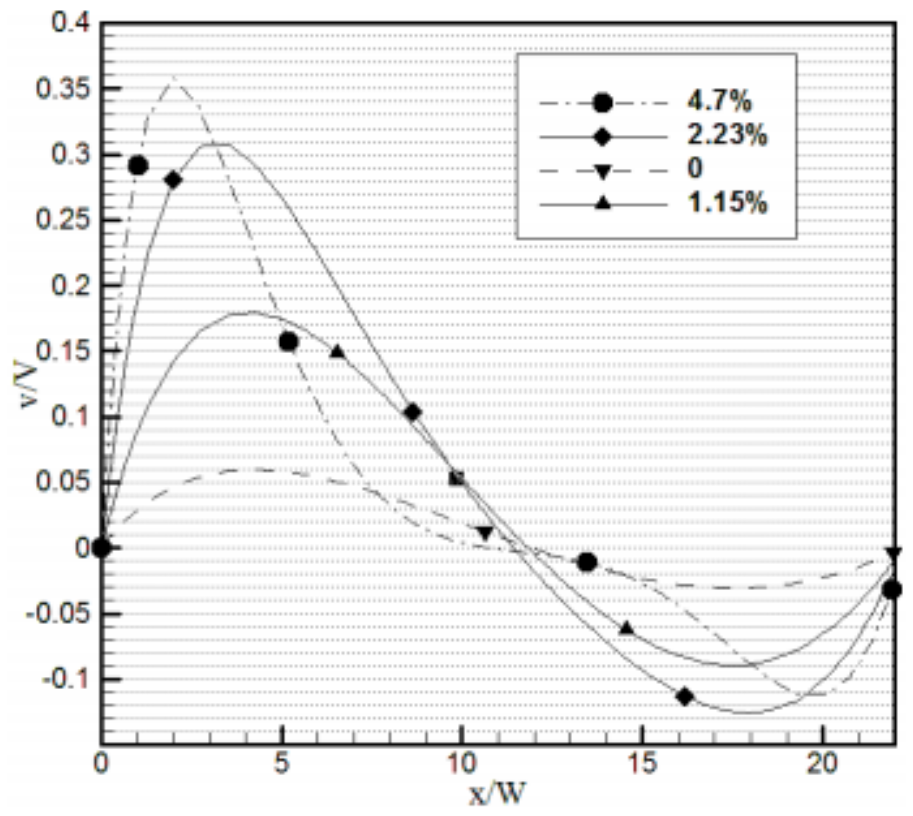

Fig. 13: Dimensioneless velocity along the radial distance for different $\phi$

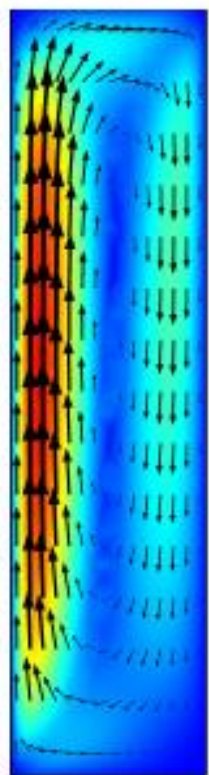

Fig. 14: Velocity field and velocity vectors for $\mathrm{Ra}=10^{6}, \mathrm{H}=20 \times 10^{3}[\mathrm{~A} / \mathrm{m}], \phi=2.23 \%$.

Fig. 15 shows the effect of magnetic forces on the MNF for different Ra numbers. It can be concluded that for higher Ra number, the effect of the magnetic force is significant and this force can destabilizes the fluid equilibrium and change the temperature gradient accordingly. 


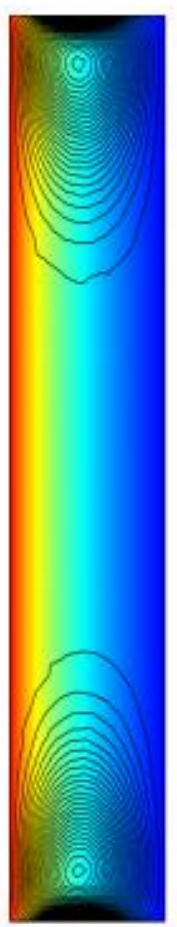

a) $\mathrm{Ra}=10^{2}$

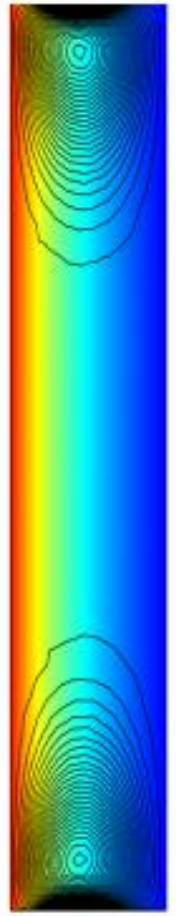

b) $\mathrm{Ra}=10^{3}$

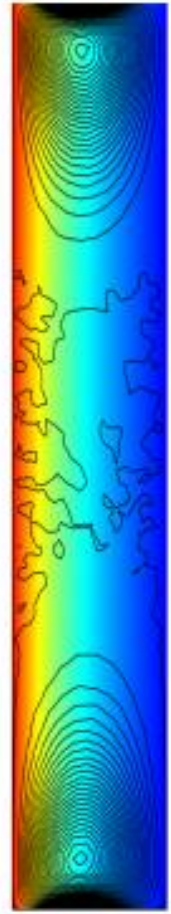

c) $\mathrm{Ra}=10^{4}$

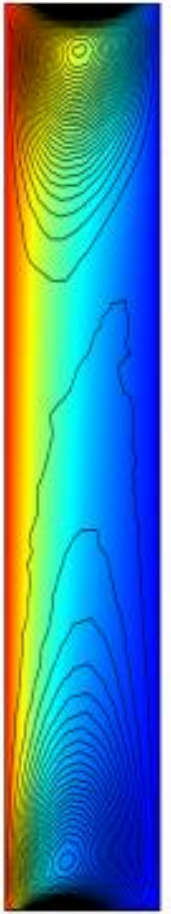

d) $\mathrm{Ra}=10^{5}$

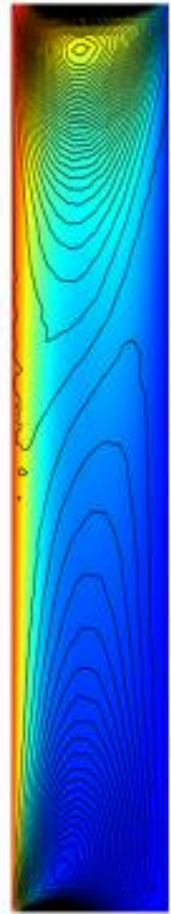

e) $\mathrm{Ra}=10^{6}$

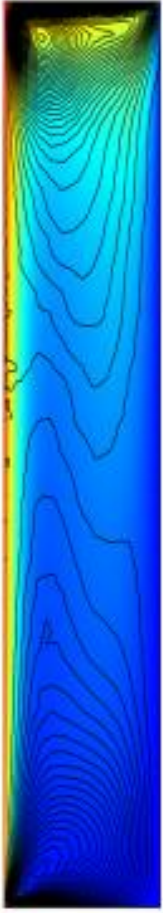

f) $\mathrm{Ra}=10^{7}$

Fig. 15: Temperature distribution and magnetization contour $\left(\phi=4.7 \%, \mathrm{H}=80 \times 10^{3}[\mathrm{~A} / \mathrm{m}]\right)$.

\section{Conclusion}

In this paper, we investigated the effect of transverse magnetic field on an annular enclosure filled with magnetic nanofluid. A nonlinear relationship between thermal conductivity and magnetic field was obtained and used in the properties of MNF. Finite element method was utilized with high mesh density near boundaries to determine the heat transfer in magnetic nanofluid assuming laminar flow and steady-state. The results show increasing the magnetic field strength and Rayleigh number both lead to increasing the Nusselt number, significantly.

\section{References}

[1] P. Keblinski, R. Prasher, and J. Eapen, "Thermal conductance of nanofluids: is the controversy over," Journal of Nanoparticle research, vol. 10, no. 7, pp. 1089-1097, 2008.

[2] H. Engler, D. Borin, and S. Odenbach, "Thermomagnetic convection influenced by the magnetoviscous effect," in Journal of Physics: Conference Series, vol. 149, p. 012105, IOP Publishing, 2009.

[3] H. Ozoe and K. Okada, "The effect of the direction of the external magnetic field on the threedimensional natural convection in a cubical enclosure," International Journal of Heat and Mass Transfer, vol. 32, no. 10, pp. 19391954, 1989.

[4] J.-J. Chieh, S.-J. Lin, and S.-L. Chen, "Thermal performance of cold storage in thermal battery for air conditioning," International journal of refrigeration, vol. 27, no. 2, pp. 120-128, 2004.

[5] H. Yamaguchi, Z. Zhang, S. Shuchi, and K. Shimada, "Heat transfer characteristics of magnetic fluid in a partitioned rectangular box," Journal of Magnetism and Magnetic Materials, vol. 252, pp. 203-205, 2002.

[6] A. Mukhopadhyay, R. Ganguly, S. Sen, and I. K. Puri, "A scaling analysis to characterize thermomagnetic convection," International Journal of Heat and Mass Transfer, vol. 48, no. 17, pp. 3485-3492, 2005.

[7] E. Blums, A. Mezulis, and G. Kronkalns, "Magnetoconvective heat transfer from a cylinder under the influence of a nonuniform magnetic field," Journal of Physics: Condensed Matter, vol. 20, no. 20, p. 204128, 2008.

[8] Z. Ming, L. Zhongliang, M. Guoyuan, and C. Shuiyuan, "The experimental study on flat plate heat pipe of magnetic working fluid,” Experimental Thermal and Fluid Science, vol. 33, no. 7, pp. 1100-1105, 2009. 
[9] D. Zablotsky, A. Mezulis, and E. Blums, "Surface cooling based on the thermomagnetic convection: Numerical simulation and experiment," International Journal of Heat and Mass Transfer, vol. 52, no. 23, pp. 5302-5308, 2009.

[10] X. Fang, Y. Xuan, and Q. Li, "Anisotropic thermal conductivity of magnetic fluids," Progress in natural science, vol. 19, no. 2, pp. 205-211, 2009.

[11] M. Ashouri, B. Ebrahimi, M. Shafii, M. Saidi, and M. Saidi, "Correlation for nusselt number in pure magnetic convection ferrofluid flow in a square cavity by a numerical investigation," Journal of Magnetism and Magnetic Materials, vol. 322, no. 22, pp. 3607-3613, 2010.

[12] Y. Iwamoto, H. Yamaguchi, and X.-D. Niu, "Magnetically-driven heat transport device using a binary temperaturesensitive magnetic fluid," Journal of Magnetism and Magnetic Materials, vol. 323, no. 10, pp. 1378-1383, 2011.

[13] A. H. Mahmoudi, I. Pop, and M. Shahi, "Effect of magnetic field on natural convection in a triangular enclosure filled with nanofluid," International Journal of Thermal Sciences, vol. 59, pp. 126-140, 2012.

[14] M. Sheikholeslami, D. Ganji, M. Gorji-Bandpy, and S. Soleimani, "Magnetic field effect on nanofluid flow and heat transfer using kk1 model," Journal of the Taiwan Institute of Chemical Engineers, vol. 45, no. 3, pp. 795-807, 2014.

[15] M. Mustafa, S. Hina, T. Hayat, and B. Ahmad, "Influence of induced magnetic field on the peristaltic flow of nanofluid," Meccanica, vol. 49, no. 3, pp. 521-534, 2014.

[16] S. Rashidi, M. Dehghan, R. Ellahi, M. Riaz, and M. Jamal-Abad, "Study of stream wise transverse magnetic fluid flow with heat transfer around an obstacle embedded in a porous medium," Journal of Magnetism and Magnetic Materials, vol. 378, pp. 128-137, 2015.

[17] W. Yu, H. Xie, L. Chen, and Y. Li, "Enhancement of thermal conductivity of kerosene-based fe 3 o 4 nanofluids prepared via phase-transfer method," Colloids and Surfaces A: Physicochemical and Engineering Aspects, vol. 355, no. 1 , pp. 109-113, 2010.

[18] T. Edwards, "kerosene" fuels for aerospace propulsion-composition and properties," in $38^{\text {th }}$ AIAA/ASME/SAE/ASEE Joint Propulsion Conference \& Exhibit, p. 3874, 2002.

[19] K. Parekh and H. S. Lee, "Magnetic field induced enhancement in thermal conductivity of magnetite nanofluid," Journal of Applied Physics, vol. 107, no. 9, p. 09A310, 2010.

[20] A. Bejan and A. D. Kraus, Heat transfer handbook, vol. 1. John Wiley \& Sons, 2003. 